Article

\title{
Factors Affecting the Popularity of Video Content on Live-Streaming Services: Focusing on V Live, the South Korean Live-Streaming Service
}

\author{
Minjeong Ham and Sang Woo Lee * \\ Graduate School of Information, Yonsei University, Seoul 03772, Korea; mnjnghm@gmail.com \\ * Correspondence: leesw726@yonsei.ac.kr; Tel.: +82-2-2123-4531
}

Received: 12 December 2019; Accepted: 23 February 2020; Published: 27 February 2020

check for updates

\begin{abstract}
Naver V Live, a South Korean live-streaming service, showcases video contents specific to the entertainment industry, such as K-pop and music. On V Live, K-pop stars and their fans can interact directly in a natural way, and V Live provides high-quality video content with novel topics. This study has identified key characteristics of video content that affect its popularity. A total of 620 video contents of five leading Star channels were classified on the basis of production company, type of video content, and whether it was live-streamed or not. The popularity of video content was measured by the number of comments, hearts, and views. To control potential bias, additional variables were set as control variables—such as the number of channel subscribers, mini-album sales, if the video content was previewed, and cumulative number of days since the video content was uploaded. For analysis, a hierarchical linear regression was conducted. The findings suggest future directions in video content planning.
\end{abstract}

Keywords: V Live; live-streaming; video content factors; video content popularity; K-pop

\section{Introduction}

With the diffusion of wireless networks and mobile devices, anyone can provide recorded video and live-streaming video content. In the past, substantial manpower and funds were required to produce video content, whereas in recent years, video content has been produced using minimum capital and mobile devices. There are various live-streaming services such as Periscope on Twitter, YouTube Live, Facebook Live, Instagram Live, Twitch, Mixer, AfreecaTV, and V Live. Periscope, YouTube Live, Facebook Live, and Instagram Live provide video content on social network services, and any user can live-stream his or her own daily life or produce entertainment content. Twitch, acquired by Amazon in 2014, is specific to game content, even though various types of content related to food, cooking, and outdoor activities were provided [1]. Microsoft's Mixer, launched in 2017, also focuses on game-related content, including E-sports, animation, and branded content [1]. AfreecaTV, the leading live-streaming service in South Korea, provides various types of video content, including "Sports," "Food Shows," "Games," and "Music." V Live, another live-streaming service in South Korea, focuses on content related to music and K-pop stars. While V Live's content is largely related to K-pop, it recently started to cover beauty and classical music content.

The distinctive feature of live-streaming is "real-time," wherein streamers and viewers can communicate directly in real-time. For example, V Live users can communicate with their favorite K-pop stars in real-time.

The demand for live-streaming services has increased due to global social network service providers like Facebook, Instagram, and YouTube actively launching live-streaming services. Numerous studies have investigated users' motives, perceived value, and attitudes for watching live-streaming content 
and users' intention to watch live-streaming content. However, no study has examined V Live services, which is the South Korean live-streaming service. V Live was launched by Naver, which is one of IT companies in South Korea and offers its own search engine. V Live focuses on entertainment content such as music and K-pop stars, whereas other live-streaming services mainly provide sports, games, and user-generated content. V Live is the only service that enables K-pop stars to live-stream in a natural manner and it provides original live-streaming content and recorded video content produced by entertainment agencies (outsourced production).

$\mathrm{V}$ Live is positively evaluated as an effective medium to advertise K-pop stars' upcoming albums, dramas, or movies [2]. When an upcoming album, drama, or movie is promoted on V Live's live-streaming services, keywords related to these upcoming works are usually ranked high in Naver's real-time search rankings, which is one of Korea's most popular search engines. As keywords rank highly in Naver's search rankings-which are extensively followed in Korea-many K-pop stars try to upload their content on V Live. However, it is not easy for any V Live content to gain popularity as several factors affect users' attention to $\mathrm{V}$ Live content.

This study aims to determine the kinds of V Live video content that gained popularity among viewers, especially focusing on characteristics of $\mathrm{V}$ Live video content. This study identifies characteristics of $\mathrm{V}$ Live's free video content and aspects of the content that attract maximum interest from $\mathrm{V}$ Live viewers. In addition, based on this study's results, we propose a direction for producing video content and budget allocation for video content production on V Live.

The rest of the paper is organized as follows. We briefly introduce practical articles and academic papers related to live-streaming services and the popularity of video content. We then describe the study's methodology, and finally, we discuss results, implications, and directions for future studies.

\section{V Live, Naver's Live-Streaming Service}

V Live was launched by Naver in August 2015; while most of its content is free, paid content has been provided since 2017. V Live started its service specifically for content related to K-pop stars and allows K-pop stars and fans to communicate directly. In addition, content planned by outsourced companies such as entertainment management agencies are also distributed on V Live, making it the only online video service to focus on K-pop stars.

In addition to live-streaming content and recorded content (not live) and collaborations with professional producers and broadcasters, $\mathrm{V}$ Live has developed original, competitive, and exclusive content. For example, using "Happy Train," K-pop stars and fans can share experiences and excitement while on a trip, and using "Lie-V," K-pop stars live-stream in their pajamas; the filming set is decorated with the star's own cherished possessions, creating a cozy atmosphere [3]. With "VS Live!", a K-pop star plays a virtual reality (VR) game wearing a VR device in a chroma key background [3], and with "Run BTS!", previously recorded, edited, and serial content relating to the South Korean hip-hop group BTS (Bangtan Boys) and original V Live content, fans can watch their favorite idols camping and gaming.

Currently, V Live's content covers beauty, classical music, and overall entertainment services. In particular, $\mathrm{V}$ Live's live-streaming service enables not only interaction between K-pop stars and fans, but also an elimination of the limit on offline space. For example, pianist Seong-Jin Cho held a recital in a small venue with 200 seats, but when it was broadcast live on V Live, approximately 100,000 cumulative viewers could appreciate his performance [4]. Moreover, the BTS concert held in London's Wembley Stadium was live-streamed on V Live, and more than 140,000 viewers watched it around the globe [5].

The demand for V Live has been increasing. According to Naver's reports, in the fourth quarter of 2017, the number of cumulative downloads surpassed 42 million. Among those viewers, overseas viewers (except South Korean viewers) accounted for $80 \%$ of total viewers, and younger viewers in the age group between 15 and 24 accounted for $79 \%$ of the total views [6,7]. In addition, according to a report by the international application analysis company App Annie, V Live sales ranked second-highest in 
South Korea and Thailand and fourth-highest in Singapore [8]. Thus, almost four years after V Live's launch, its performance is gradually emerging, suggesting that it is securing a position as a global entertainment platform. So far, $\mathrm{V}$ Live has been developing video content related to the entertainment services, and we focus on V Live's "Star channels" which are owned and run by K-pop stars.

\section{Related Studies}

\subsection{Live-Streaming Service}

While interactive communication between broadcasters and viewers was impossible in traditional broadcasting networks, it is possible in real-time on live-streaming services on a wireless network $[9,10]$. Live streaming enables direct communication between streamers and viewers and aims to exploit interactivity among viewers [11]. With Facebook, Instagram, and YouTube starting live-streaming services such as Facebook Live, Instagram Live, and YouTube live, live-streaming has become increasingly accessible and common. For example, Instagram users can become streamers by clicking the button up to three times. In other words, anyone with a social network service (SNS) account and a mobile device can become a streamer.

Previous studies on live-streaming services usually focused on the perspective of live-streaming viewers (See Table 1), specifically on their motives to watch live-streaming, engagement during watching live-streaming services, attitudes and perceived value towards live-streaming services [12-14]. The relationship between streamers and viewers have also been examined. During live-streaming, streamers and viewers are able to communicate directly, and the interaction facilitates bonding between streamers and viewers. The continuous watching intention was explained with the identification with either broadcaster (i.e., sense of yearning) or group (i.e., sense of community). The stronger the identification with the broadcaster or the group, the higher the continuous watching intention [15].

\subsection{Characteristics of Video Content}

The characteristics of live-streaming content were also investigated. The types of live-streaming content refer to the style and information characteristics of video content [16]. In previous studies, live-streaming contents of Periscope, Ustream, and YouNow were classified as follows: "To Chat" for communication between streamer and viewers, "Share Information," to share information with viewers, "24/7," to observe $24 \mathrm{~h}$ a day, seven days a week, and "Slice of Life," to broadcast the streamer's daily life [17]. Other categories included "Entertainment Media," "Make Music," "Animals," "Nature," "Gaming," "Sports," "News," "Spirituality," "Advertising," "Food," “Comedy," "Fitness," "Politics," "Business Information," "Science, Technology, Medicine (STM)," "Draw/Paint a Picture," and "Nothing" [17]. Among 21 categories of live-streaming contents, "To Chat" accounted for the highest percentage $(44.02 \%)$ and was considered to be the main content category [17]. In another study, 767 live-streaming contents of Meerkat and Periscope were classified into the following 21 categories [18]: "Chatting"; "Object, place, animal, etc."; "Activity, craft, skill, etc."; "Funny activity or event"; "Ask me anything (AMA)"; "Walking around"; "Showing scenery"; "Behind the scenes"; "Party or social gathering"; "Live news event"; "In a vehicle"; "How-to"; "Amateur sports, concerts, etc."; "Recurring or regular stream"; "Cooking or preparing food"; "Weather"; "Dining or eating food"; "Professional performance"; "Audience participation"; "Talk show"; and "Gaming."

Live-streaming services such as Periscope, AfreecaTV, and YouNow investigated in previous studies do not have an entry barrier for streamers $[13,14,17]$. There is no concept of "Original content" in such live-streaming services, but the video contents can be generated as desired by the streamer, and the video contents are mostly live-streaming, not recorded [17]. To produce video content on such live-streaming services, high costs and professional skills are not required. 
Table 1. Summary of previous studies on live-streaming services.

\begin{tabular}{|c|c|c|c|c|}
\hline Research & Objective & Methodology & Context & Findings \\
\hline [12] & $\begin{array}{l}\text { Live-streaming viewers' } \\
\text { motivation of } \\
\text { engagement, depending } \\
\text { on the size of the } \\
\text { live-streaming channel. }\end{array}$ & Survey & Twitch & $\begin{array}{l}\text { The higher the motivation, such } \\
\text { as social interaction, sense of } \\
\text { community, meeting new } \\
\text { people, entertainment, } \\
\text { information seeking, and } \\
\text { external support, the more } \\
\text { engagement, such as emotional } \\
\text { connectedness, watching, } \\
\text { subscribing, and donating. } \\
\text { The relationship between social } \\
\text { motivations and the viewer } \\
\text { engagement differ depending on } \\
\text { the channel sizes. }\end{array}$ \\
\hline [13] & $\begin{array}{l}\text { The effect of viewers' } \\
\text { engagement on gifting } \\
\text { items to a streamer in } \\
\text { live-streaming services. }\end{array}$ & $\begin{array}{l}\text { Objective data } \\
\text { (User data) } \\
\text { analysis }\end{array}$ & $\begin{array}{l}\text { AfreecaTV } \\
\text { (South } \\
\text { Korean } \\
\text { service) }\end{array}$ & $\begin{array}{l}\text { The viewer engagement } \\
\text { positively affects gift-giving } \\
\text { decisions. } \\
\text { The impact of viewer } \\
\text { engagement on the number of } \\
\text { gifts purchased depending on } \\
\text { how the engagement is } \\
\text { measured. }\end{array}$ \\
\hline [14] & $\begin{array}{l}\text { The influential factors } \\
\text { affecting audiences to } \\
\text { watch live-streaming } \\
\text { events: attitude, } \\
\text { perceived value, and } \\
\text { intention to watch. }\end{array}$ & Survey & $\begin{array}{l}\text { Social } \\
\text { network } \\
\text { service }\end{array}$ & $\begin{array}{l}\text { Attitude mediates the } \\
\text { relationship between } \\
\text { entertainment and intention to } \\
\text { watch, and between social } \\
\text { interaction and intention to } \\
\text { watch. } \\
\text { Perceived value mediates the } \\
\text { relationship between flow and } \\
\text { intention to watch. }\end{array}$ \\
\hline [15] & $\begin{array}{l}\text { Audiences' continuous } \\
\text { watching intention via a } \\
\text { dual identification } \\
\text { framework. }\end{array}$ & Survey & $\begin{array}{l}\text { Douyu TV, } \\
\text { YY Live } \\
\text { (Chinese } \\
\text { service) }\end{array}$ & $\begin{array}{l}\text { The stronger broadcaster } \\
\text { identification and group } \\
\text { identification were, the higher } \\
\text { continuous watching intention } \\
\text { was. } \\
\text { The moderating effect of genre } \\
\text { existed in video game streaming } \\
\text { services. }\end{array}$ \\
\hline
\end{tabular}

\begin{tabular}{|c|c|c|c|c|}
\hline [17] & $\begin{array}{l}\text { Streamer's motives to } \\
\text { use streaming services } \\
\text { depending on both } \\
\text { content types and } \\
\text { countries (the U.S., } \\
\text { Germany, Japan). }\end{array}$ & $\begin{array}{l}\text { Content } \\
\text { analysis }\end{array}$ & $\begin{array}{l}\text { Periscope, } \\
\text { Ustream, } \\
\text { YouNow }\end{array}$ & $\begin{array}{l}\text { The main motives to use } \\
\text { streaming services are "to } \\
\text { relieve boredom" and } \\
\text { "Socializing," and the main } \\
\text { content was "To chat." }\end{array}$ \\
\hline [18] & $\begin{array}{l}\text { To examine the content, } \\
\text { setting, and other } \\
\text { characteristics of } \\
\text { live-streams. }\end{array}$ & $\begin{array}{c}\text { Survey for } \\
\text { users (Crowded } \\
\text { sourced coding } \\
\text { of live-stream), } \\
\text { Interview for } \\
\text { streamer }\end{array}$ & $\begin{array}{l}\text { Meerkat, } \\
\text { Periscope }\end{array}$ & $\begin{array}{l}\text { The most frequently shown } \\
\text { content category on } \\
\text { live-streaming service was } \\
\text { "Chatting," and the setting was } \\
\text { "Indoor." } \\
\text { The interaction during } \\
\text { live-streaming was "Streamer } \\
\text { actively responded to incoming } \\
\text { comments in some way." }\end{array}$ \\
\hline
\end{tabular}


Instead, V Live has an entry barrier to become a streamer, and a contract between V Live and a streamer (or an entertainment management agency) is necessary to start a channel. Only authorized individuals may own channels on $\mathrm{V}$ Live. As mentioned in Section 2, to enhance its own competitiveness among various online video services, $\mathrm{V}$ Live has been developing its own original content with novel topics by collaborating with professional producers and outsourced companies, such as entertainment management agencies. V Live's content is produced in three ways: no production company (created by the streamer him/herself), V Live, and outsourced companies (See Table 2). Except for video content without a production company, the other two types of video content are live-streaming and recorded content [9]. The latter especially requires higher costs and time, including editing, subtitling, inserting background music, and inserting special effects.

Although previous studies have investigated characteristics of live-streaming content, few studies have examined entertainment-specific video content such as V Live, which is a mix of pre-planned and unplanned video content. Emerging popularity of $\mathrm{V}$ Live implies the popularity of K-pop stars and competitive video content of $\mathrm{V}$ Live. The goal of this study is to investigate the main factors that lead to success on $\mathrm{V}$ Live. In particular, we focus on the types of $\mathrm{V}$ Live content that is more attracted to consumers. The higher number of comments, hearts, and views $V$ Live has, the more popular $V$ Live is. A V Live's "Heart" is the equivalent of a YouTube's "Like." We try to discover factors affecting the popularity of video content, and it is necessary to classify and identify the types of video content provided on V Live. Based on previous studies and data collected for this study, video content of $\mathrm{V}$ Live was classified into several categories (See Table 2).

\subsection{Popularity of Video Content}

The degree of viewer engagement is one of those measurements to evaluate the performance of the video content. For example, when users watch YouTube content, the number of views of that content may be equivalent to the popularity of YouTube content. Similarly, when users press "like", comment, and share YouTube content, the number of "likes", comments, and shares are another measure of the content's popularity. Based on these users' activities such as "like", "comment", and "share", YouTube accordingly presents popular video content on its website or mobile app. Researchers have examined factors affecting the popularity of YouTube's video content [16]. In these studies, the popularity of YouTube's video content was measured by the number of views, comments, subscriptions, shares, and total number of ratings [16]. Although video content with more views, likes, comments, or shares may not be the best content, this content may be popular content preferred by numerous YouTube users [19]. In other words, these measures can be objective indices to reflect the popularity of video content.

On the other hand, the influence of video content can be determined by the rate of reach to viewers, but the reaching rate cannot be guaranteed [16]. Thus, the rate of reach to viewers can be measured by the number of subscribers and views [20]. V Live users, similar to YouTube users, can watch video content, press the "Heart," comment, and share their favorite content.

Based on the popularity of video content, V Live has selected the "Top 10" Global Artists on Star channel since 2017. The popularity of video content on V Live is measured by the total number of views, comments, and hearts on Star channel as well as fans' attendance rate. V Live fans enthusiastically participate in viewing, commenting, and pressing hearts for their favorite stars to be selected as "Top 10" artists. In particular, the V Live "Heart" is considered to be the most important measure of popularity of K-pop stars, and for the estimation for fandom size. The popularity of each member of an idol group is also estimated by the number of hearts, even within the same group [7]. Unlike YouTube, V Live does not provide the number of shares of the content.

As Pareto principle implies, a small number of popular channels have produced most of V Live's contents, and viewers have intensively and disproportionately played and favored the video content of these popular channels. In 2006, the number of views for the top 3\% of YouTube channels accounted for $64 \%$ of the number of all YouTube views; this rose to $90 \%$ in 2016 [21,22]. Like on YouTube, the top ten of more than 1400 Star channels on V Live are selected for awards based on their popular content. 
This study selected the top five V Live channels to analyze the free video content of each top-five channel and investigated which content factor gained popularity with viewers. This study aims to examine which factors matter for the popularity of video content in the context of Naver V Live. This study identified the following research question:

Research Question: Which content factors (i.e., types of video content, production company, and live-streamed or recorded) have influenced the popularity of video content (i.e., number of views, comments, and hearts) on V Live?

\section{Research Methodology}

\subsection{Selection of the Top Five V Live Channels}

In 2018, the top-ten K-pop stars (or groups) were honorably selected as the "Global Artist Top 10," based on total scores of views, hearts, and comments on the video content, and fan attendance rate on each Star channel between January 1 and December 25, 2017. Fan attendance rate is a measure of how often fans visit their favorite K-pop star's channel. However, details of the proportions of each score were not disclosed. In addition, V Live measures the popularity of each Star channel in the top three countries (See Figure 1). This study focused on the five most popular Star channels in South Korea. Other countries (China, the U.S., the Philippines, and Thailand) were excluded as cultural differences and market conditions could not be controlled for. Thus, the following top five K-pop groups were selected for this study: BTS, Nu'est, SEVENTEEN, GFRIEND, and TWICE.

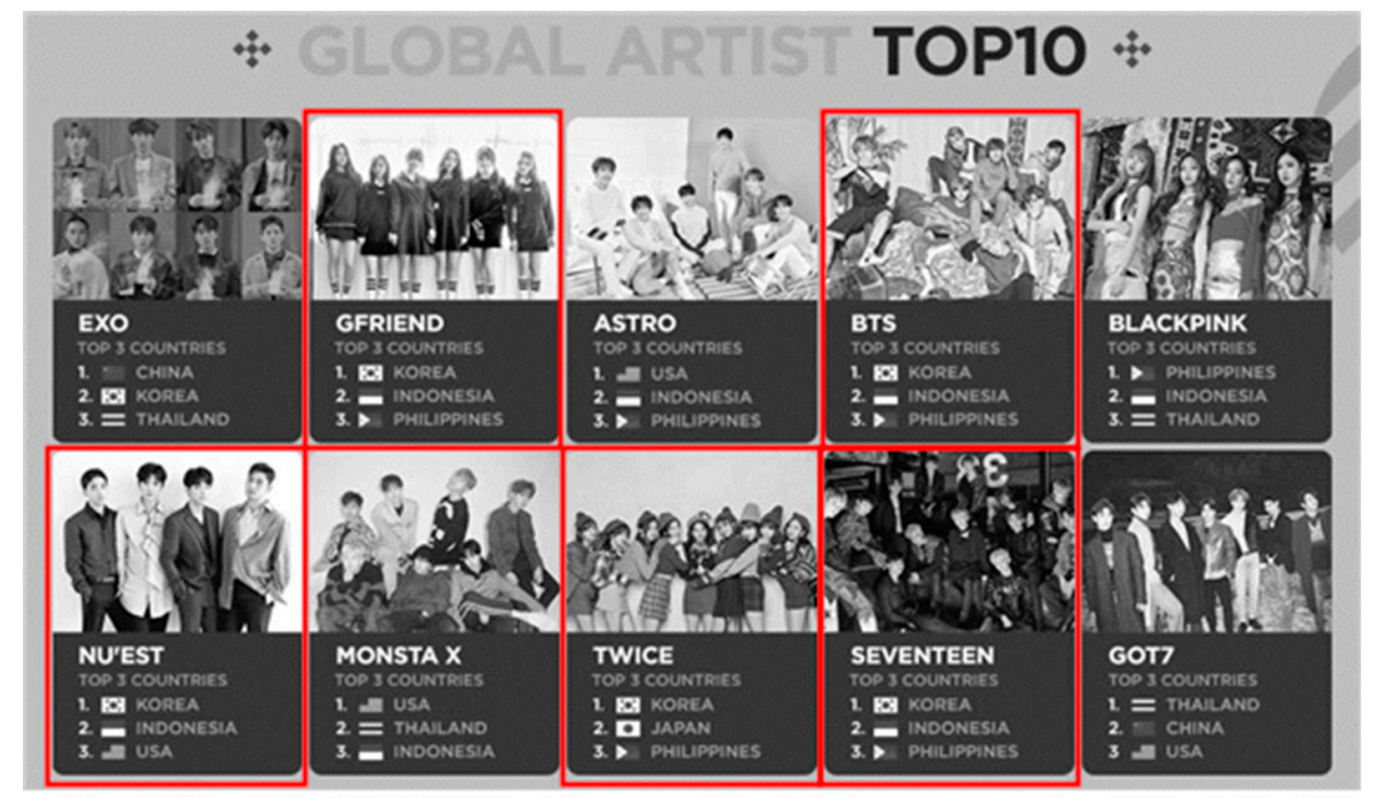

Figure 1. Global Artist Top 10 in 2018.

\subsection{Data Coding}

We coded only for video content that met the criteria for this study. The criteria were as follows: (1) paid video content was excluded; (2) video clips edited from full versions of live-streamed content with the "V Pick" logo were excluded, because they were not newly uploaded; and (3) re-uploaded video clips from the past, edited, and trending in live-streaming were excluded because they were not newly uploaded (e.g., BTS from two years ago, Nu'est from two years ago). In 2017, the total video content on the top five Star channels was 1224; of these, 620 videos were selected for coding in accordance with the criteria. The following data were coded for each video. There were three independent variables for content factors: 1) production company, 2) type of video content, and 3) whether the video content was live-streamed. The three dependent variables indicating the popularity 
of video content were: 1) number of comments, 2) hearts, 3) views. For each video content, the following factors were coded:

\section{- $\quad$ Characteristics of video content (IV)}

- $\quad$ Video content production company: 3 categories

- $\quad$ Type of video content: 8 categories

- $\quad$ Video content live-streamed or not: 2 categories

\section{- Popularity of video content (DV)}

$\begin{array}{ll}-\quad & \text { Number of comments } \\ \text { - } \quad & \text { Number of hearts } \\ -\quad & \text { Number of views }\end{array}$

The first independent variable, production company, identified whether a production company produced the video content and the type of company. There were three options. Some video content was produced without a production company, as in the case of free-style live-streaming. Video content was also produced by $\mathrm{V}$ Live itself and by outsourced companies such as entertainment management agencies (See Table 2).

The second independent variable, type of video content, was categorized into a total of eight types based on previous studies $[16,17,23-25]$. All 620 videos were classified into mutually exclusive sub-categories (See Table 2).

The eight types of video content were as follows: (1) Free-style live-streaming, (2) Music/Choreography, (3) Offline event-related live-streaming, (4) Series-edited video content, (5) Non-series-edited video content, (6) Series live-streaming, (7) Non-series live-streaming, and (8) Others.

(1) Free-style live-streaming focuses on a K-pop star at home or in a car in a casual manner, without a purpose or script. In such a case, the K-pop star suddenly starts live-streaming without any notice and without the participation of a production company. (2) Music/Choreography is pre-edited video content with no subtitles such as dance performances, music videos, and voices of K-pop stars. (3) Offline event-related live-streaming is live broadcasting of events held offline, such as concerts and press conferences. (4) Series-edited video content is an edited series of broadcasts for which the content, script, and subtitles are clearly planned; these are produced by outsourced companies such as entertainment management agencies. (5) Non-series-edited video content consists of edited one-off broadcasts with planned content, scripts, and subtitles produced by outsourced companies such as entertainment management agencies. (6) Series live-streaming is a series of live broadcasts for which the content and script are planned, unlike free-style live-streaming. This video content is produced not only by V Live, but also by outsourced companies such as entertainment management agencies. (7) Non-series live-streaming is a category of one-off live broadcasts for which the content and script are clearly planned. Such video content is produced by outsourced companies (such as entertainment management agencies) and by V Live. (8) The "Others" category includes short video content that K-pop stars provide to fans such as holiday greetings and encouragement for college entrance exams.

The third independent variable, "whether a video content is live-streamed or not," indicates whether a video content is not a recording but a live broadcast. Compared to other services, V Live provides both K-pop-specific video content that enables viewers to communicate directly with stars, and that V Live or outsourced companies have previously filmed, edited, and subtitled. As one characteristic of video content, we examined whether live-streaming content gains more popularity than recorded video content, or vice versa. Among eight types of video content, free-style live-streaming, offline event-related live-streaming, series live-streaming, and non-series live-streaming are all live (Dummy variable $=0$ ). Four additional content types, music/choreography, series-edited video content, non-series-edited video content, and "others" are previously recorded (Dummy variable $=1$ ). 
Table 2. Characteristics of video content.

\begin{tabular}{|c|c|c|c|c|c|}
\hline $\begin{array}{l}\text { Types of } \\
\text { Video Content }\end{array}$ & Definition & $\begin{array}{l}\text { Production } \\
\text { Company }\end{array}$ & $\begin{array}{l}\text { Live-Streamed } \\
\text { or Recorded }\end{array}$ & $\begin{array}{l}\text { Frequency } \\
\text { (EA) }\end{array}$ & Percentage $(\%)$ \\
\hline $\begin{array}{l}\text { Free-style } \\
\text { live-streaming }\end{array}$ & $\begin{array}{l}\text { K-pop star live-streams casually } \\
\text { at home or in a car } \\
\text { No script } \\
\text { No episodes }\end{array}$ & No & Live-streamed & 212 & 34.2 \\
\hline $\begin{array}{l}\text { Music/ } \\
\text { Choreography }\end{array}$ & $\begin{array}{l}\text { Previously edited } \\
\text { No subtitles } \\
\text { Voice, Music videos, Dance }\end{array}$ & $\begin{array}{l}\text { Outsourced } \\
\text { company }\end{array}$ & Recorded & 133 & 21.5 \\
\hline $\begin{array}{l}\text { Offline event- } \\
\text { related } \\
\text { live-streaming }\end{array}$ & $\begin{array}{l}\text { Live broadcast of offline event, } \\
\text { e.g., concert, press conference }\end{array}$ & $\begin{array}{l}\text { Outsourced } \\
\text { company }\end{array}$ & Live-streamed & 35 & 5.6 \\
\hline $\begin{array}{l}\text { Series-edited } \\
\text { video content }\end{array}$ & $\begin{array}{l}\text { Clearly pre-planned video } \\
\text { content } \\
\text { Episodes/Script/Subtitles }\end{array}$ & $\begin{array}{l}\text { V Live, } \\
\text { Outsourced } \\
\text { company }\end{array}$ & Recorded & 112 & 18.1 \\
\hline $\begin{array}{l}\text { Non-series-edited } \\
\text { video content }\end{array}$ & $\begin{array}{l}\text { Clearly pre-planned video } \\
\text { content } \\
\text { One-off/No episodes } \\
\text { Script/Editing point/Subtitle }\end{array}$ & $\begin{array}{l}\text { Outsourced } \\
\text { company }\end{array}$ & Recorded & 41 & 6.6 \\
\hline $\begin{array}{l}\text { Series } \\
\text { live-streaming }\end{array}$ & $\begin{array}{l}\text { Clearly pre-planned video } \\
\text { content } \\
\text { Script } \\
\text { Episodes/Subtitles }\end{array}$ & $\begin{array}{l}\text { V Live, } \\
\text { Outsourced } \\
\text { company }\end{array}$ & Live-streamed & 32 & 5.2 \\
\hline $\begin{array}{l}\text { Non-series } \\
\text { live-streaming }\end{array}$ & $\begin{array}{l}\text { Clearly pre-planned video } \\
\text { content } \\
\text { Script } \\
\text { One-off/No episodes }\end{array}$ & $\begin{array}{l}\text { V Live, } \\
\text { Outsourced } \\
\text { company }\end{array}$ & Live-streamed & 32 & 5.2 \\
\hline Other & $\begin{array}{l}\text { To send good wishes to fans } \\
\text { (holiday greetings, best wishes } \\
\text { for college entrance exams) }\end{array}$ & $\begin{array}{l}\text { Outsourced } \\
\text { company }\end{array}$ & Recorded & 23 & 3.7 \\
\hline Total & & & & 620 & 100.0 \\
\hline
\end{tabular}

We controlled several factors affecting the dependent variable. Judging from the new fandom trend, "Heart Labor [7]," the video content of K-pop stars with large fandoms is preferred and viewed more than that of K-pop stars with small fandoms. "Heart Labor" describes the act of quickly pressing the heart button on V Live to increase the number of hearts. During live-streaming on V Live, fans cannot send cyber money (as with AfreecaTV's "Star Balloons" or Twitch's "Donations") to K-pop stars; instead, V Live viewers press the "hearts," which indicates the popularity of video content and that of their favorite K-pop stars. To investigate the effect of V Live content on dependent variables, it is necessary to control for the popularity of K-pop stars themselves. Specifically, as the selected top-five channels were all vocal groups, the number of $\mathrm{V}$ Live channel subscribers and mini-album sales for each group were used to measure the popularity of the K-pop groups.

The number of $\mathrm{V}$ Live channel subscribers indicates how many V Live viewers subscribe to each channel; this variable can be used to measure the popularity of each K-pop group. Since the number of channel subscribers varies from hour to hour each day, we used the value on June 1, 2018 when the data were collected. At that time, there were 11,034,567 BTS channel subscribers; 3,386,062 SEVENTEEN channel subscribers; 2,487,123 TWICE channel subscribers; 739,048 GFRIEND channel subscribers; and $702,408 \mathrm{Nu}^{\prime}$ est channel subscribers.

The album-sales variable indicates the number of albums sold by each K-pop group in 2017. In this study, album sales were based on Gaon Music Chart. Gaon Music Chart is a South Korean official music chart published by Korea Music Content Association (KMCA), which is affiliated to the Ministry of Culture, Sports, and Tourism; they consider it necessary to have an official domestic music chart, like the U.S. Billboard chart and Japan's Oricon music chart. The Gaon Chart monitors album sales by counting the number of released records minus the number of returned records. The 
number and type of albums released by K-pop groups in 2017 were different. TWICE released two repackaged albums, one mini-album, and one regular album; total album sales were 1,048,746, and mini-album sales were 285,294 . Nu'est released only one mini-album; thus, total album sales and mini-album sales were 308,108. Regular albums, repackaged albums, and mini-albums are different in character and not comparable. Total album sales and mini-album sales showed a high correlation; the correlation coefficient was $0.910(p<0.000)$. The presence of highly correlated independent variables in a regression equation can lead to multicollinearity problems. To compare album sales of the five K-pop groups, mini-album sales were set as an album-sales variable, based on $\mathrm{Nu}^{\prime}$ est, which released only one mini-album.

Variables such as "previewed or not" and "cumulative number of days since video content was uploaded" were also controlled for in this study. "Previewed or not" indicates whether the video content was uploaded after a preview. On previewed live-streaming, viewers can press "hearts" before the live-streaming begins. In either case, the heart button can be pressed after live-streaming ends [7]. For previewed video content, data include the number of hearts and comments accumulated before live-streaming begins; for non-previewed video content, data include only those hearts and comments that accumulate after live-streaming begins.

The "cumulative number of days since video content was uploaded" indicates the period from when the video content was uploaded to when the study data were collected. Data used in this study were collected in June 2018, not when the video content was uploaded. In other words, depending on when the video content was uploaded, viewers may have had more or less time to repeat the video content, comment on it, or press the heart button. For example, it is assumed that video content A was uploaded in January 2017, and video content B was uploaded in December 2017. As this study's data were collected in June 2018, video content A had been online for 18 months, while video content B had been online for only six months. There was thus a gap of 12 months (one year) between uploads of video contents A and B. As a result, the popularity of video content A reflected the number of comments, views, and hearts accumulated over an 18-month period since upload, while the popularity of video content $B$ reflected the same data gathered over a six-month period. To address these time gaps, the variable "cumulative number of days since video content was uploaded" was used to control the number of comments, views, and hearts indicating the popularity of video content.

\subsection{Data Analysis}

To find the answer for the research question, we conducted a hierarchical linear regression. The adoption of a hierarchical model allowed us to examine if each variable explains a statistically significant amount of variance in each dependent variable after considering for all other variables. Formally, we specify our hierarchical linear regression model as follows:

(Model 1) $\ln \left(\mathrm{Y}_{\mathrm{i}}\right)=\alpha^{*} \ln \left(\mathrm{X}_{\mathrm{cv}}\right)+\mathrm{e}$,

(Model 2) $\ln \left(\mathrm{Y}_{\mathrm{i}}\right)=\alpha^{*} \ln \left(\mathrm{X}_{\mathrm{cv}}\right)+\beta \mathrm{X}_{\mathrm{pc}}+\mathrm{e}$,

(Model 3) $\ln \left(\mathrm{Y}_{\mathrm{i}}\right)=\alpha^{*} \ln \left(\mathrm{X}_{\mathrm{cv}}\right)+\beta \mathrm{X}_{\mathrm{pc}}+\tau \mathrm{X}_{\mathrm{ct}}+\mathrm{e}$,

(Model 4) $\ln \left(\mathrm{Y}_{\mathrm{i}}\right)=\alpha^{*} \ln \left(\mathrm{X}_{\mathrm{cv}}\right)+\beta \mathrm{X}_{\mathrm{pc}}+\tau \mathrm{X}_{\mathrm{ct}}+\gamma \mathrm{X}_{\mathrm{st}}+\mathrm{e}$,

where $\mathrm{i}$ is the individual video content, $\mathrm{Y}$ is the popularity of video content (i.e., number of comments, hearts, and views), $X_{\mathrm{cv}}$ is variables denoting control variables (i.e., number of channel subscribers, mini-album sales, previewed or not, and cumulative number of days after video content uploaded), $X_{\mathrm{pc}}$ is a dummy variable denoting three production companies, $\mathrm{X}_{\mathrm{ct}}$ is a dummy variable denoting eight types of video content, and $X_{\mathrm{st}}$ is a dummy variable denoting video content live-streamed or not. Due to the skewedness of dependent variables, most variables except for dummy variables were log-transformed. 


\section{Empirical Results}

By analyzing 620 free video contents of the top five Star channels in 2017, this study aimed to examine which factors affect the popularity of video content. A hierarchical regression analysis was conducted with three independent variables indicating the characteristics of video content (i.e., production company, types of video content, and live-streamed or not). There were three dependent variables indicating the popularity of video content (i.e., number of comments, hearts, and views), and four control variables (i.e., number of channel subscribers, mini-album sales, whether the video content was previewed, and cumulative number of days after the video content was uploaded).

Before the regression analysis, we conducted a frequency analysis, a descriptive analysis, and a correlation analysis to understand the composition of the data. As Table 2 indicates, of a total of 620 videos posted on the top five Star V Live channels, 212 were free-style broadcasting (34.2\%), 133 were music/choreography ( $21.5 \%)$, and 112 were series-edited video content (18.1\%). In addition, as Table 3 indicates, the average number of comments was $149,949.98$ (S.D. $=327,847.36$ ), the average number of hearts was 13,146,072.98 (S.D.35,194,871.76), and the average number of views was $541,766.79$ (S.D.1,017,211.20).

Table 3. Descriptive statistics for dependent variables.

\begin{tabular}{lcccc}
\hline & Min & Max & Mean & S.D. \\
\hline Number of comments & 443 & $3,205,652$ & $149,949.98$ & $327,847.36$ \\
Number of hearts & 142 & $402,183,032$ & $13,146,072.98$ & $35,194,871.76$ \\
Number of views & 14 & $6,333,309$ & $541,766.79$ & $1,017,211.20$ \\
\hline
\end{tabular}

Concerning the skewedness of dependent variables (i.e., number of comments, hearts, and views), we transformed dependent variables into logarithms, and conducted a Pearson correlation analysis to examine the relationships between variables (See Table 4). The correlation coefficients between dependent and independent variables were generally significant. In other words, a significant effect was discovered between the characteristics and the popularity of V Live's video content.

Table 4. Pearson correlation matrix.

\begin{tabular}{|c|c|c|c|c|c|c|c|c|c|c|c|c|}
\hline & 2 & 3 & 4 & 5 & 6 & 7 & 8 & 9 & 10 & 11 & 12 & 13 \\
\hline 1. Comments & $0.83^{* *}$ & $0.59^{* *}$ & $-0.20^{* *}$ & $0.35^{* *}$ & $-0.33^{* *}$ & $0.15^{* *}$ & -0.06 & 0.06 & $0.28^{* *}$ & $-0.19^{* *}$ & $-0.24^{* *}$ & $-0.50^{* *}$ \\
\hline 2. Hearts & 1 & $0.60^{* *}$ & $-0.16^{* *}$ & $0.10^{*}$ & $-0.31^{* *}$ & 0.05 & $0.21^{* *}$ & 0.05 & $0.25^{* *}$ & -0.07 & $-0.20^{* *}$ & $-0.20^{* *}$ \\
\hline 3. Views & & 1 & -0.07 & 0.04 & $-0.13^{* *}$ & $-0.10^{*}$ & $0.26^{* *}$ & -0.60 & 0.07 & -0.07 & $-0.17^{* *}$ & -0.03 \\
\hline 4. V Live & & & 1 & $-0.21^{* *}$ & $0.09^{*}$ & $-0.19^{* *}$ & 0.08 & 0.04 & $-0.38^{* *}$ & 0.04 & 0.03 & $0.16^{* *}$ \\
\hline 5. Outsourced & & & & 1 & $-0.40^{* *}$ & $-0.11^{*}$ & $-0.36^{* *}$ & $0.10^{*}$ & 0.03 & $-0.21^{* *}$ & $-0.15^{* *}$ & $-0.77^{* *}$ \\
\hline 6. Music/choreography & & & & & 1 & $-0.12^{* *}$ & $-0.24^{* *}$ & $-0.13^{* *}$ & $-0.12^{* *}$ & $-0.14^{* *}$ & $-0.10^{*}$ & $0.52^{* *}$ \\
\hline 7. Series Live-streaming & & & & & & 1 & $-0.11^{* *}$ & -0.06 & -0.05 & -0.06 & -0.05 & $-0.23^{* *}$ \\
\hline 8. Series-edited & & & & & & & 1 & $-0.12^{* *}$ & $-0.11^{* *}$ & $-0.13^{* *}$ & $-0.09^{*}$ & $0.47^{* *}$ \\
\hline 9. Offline-related & & & & & & & & 1 & -0.06 & -0.07 & -0.05 & $-0.23^{* *}$ \\
\hline $\begin{array}{l}\text { 10. Non-series } \\
\text { live-streaming }\end{array}$ & & & & & & & & & 1 & -0.07 & -0.05 & $-0.23^{* *}$ \\
\hline 11. Non-series edited & & & & & & & & & & 1 & -0.05 & 0.27 \\
\hline 12. Others & & & & & & & & & & & 1 & $0.20 * *$ \\
\hline 13. Live-streamed or not & & & & & & & & & & & & 1 \\
\hline
\end{tabular}

1. Dependent variables are log-transformed: \#1-3; 2. Reference variable of \#4, 5 (No production company = 0);

3. Reference variable of \#6-12 (Free-style live-streaming = 0); 4. Reference variable of \#13 (Not live-streamed =0);

5. Statistical significance: ${ }^{*} p<0.05,{ }^{* *} p<0.01$.

When the dependent variable was the number of comments, Model 1 of Table 5 presents that "mini-album sales $(\beta=1.046 ; p<0.000)$ " and "cumulative number of days after video content uploaded ( $\beta=0.239 ; p<0.01)^{\prime \prime}$, control variables, had a positive effect on the popularity of video content; however, "previewed or not," which was also a control variable, had a negative effect $(\beta=-0.653 ; p<0.01)$. Model 2 shows that video content without a production company had a greater positive impact on its popularity than video content produced by V Live $(\beta=-0.139 ; p<0.000)$ and by outsourced companies 
$(\beta=-0.474 ; p<0.000)$. It can be inferred that video contents made without any production plans are generally broadcasts that a streamer starts live-streaming to communicate with viewers without any preview; the way viewers can communicate with a streamer is by commenting, and this type of video content can drive more comments from viewers. Model 3 presents that free-style live-streaming had a greater positive impact on video content popularity than Music/Choreography $(\beta=-1.432 ; p<0.000$ ), Series-edited video content $(\beta=-1.221 ; p<0.000)$, Non-series edited video content $(\beta=-1.495$; $p<0.000)$, or "Others" $(\beta=-1.932 ; p<0.000)$. Conversely, non-series live-streaming won more popularity than free-style live-streaming $(\beta=0.974 ; p<0.000)$. Model 4 shows that whether a video is live-streamed had no significant impact on its popularity.

Table 5. Hierarchical regression $(\mathrm{DV}=\log$ (number of comments)).

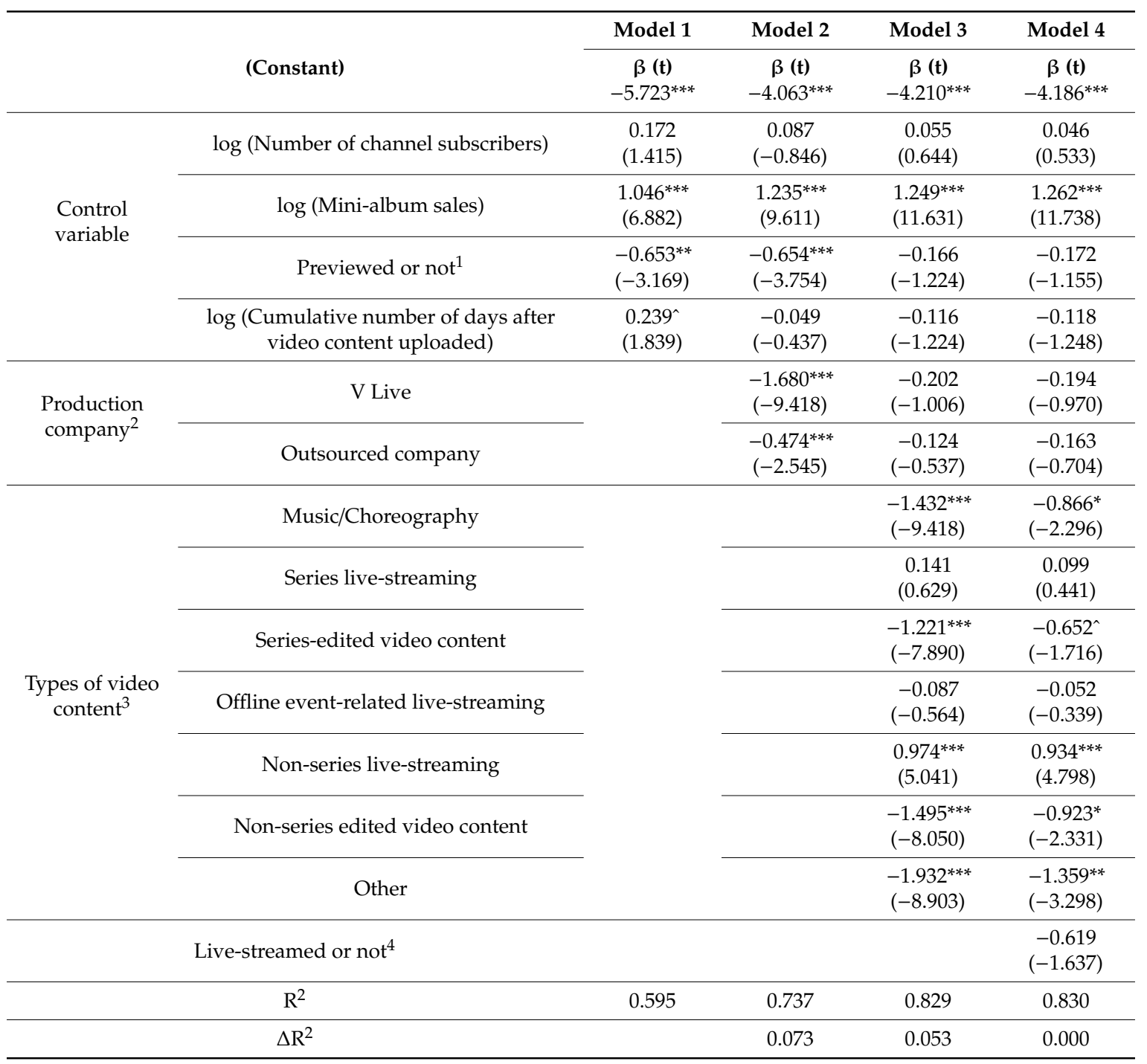

1. Reference variable of Model 1 (dummy variable; previewed = 0); 2 . Reference variable of Model 2 (dummy variable; no production company $=0$ ); 3 . Reference variable of Model 3 (dummy variable; free-style live-streaming $=0$ ); 4. Reference variable of Model 4 (dummy variable; not live-streamed $=0$ ); 5 . Statistical significance: ${ }^{\wedge} p<0.10$, ${ }^{*} p<0.05,{ }^{* *} p<0.01,{ }^{* * *} p<0.001$.

When the dependent variable was the number of hearts, Model 1 of Table 6 reports that "previewed or not" $(\beta=-0.856 ; p<0.000)$, and "cumulative number of days after the video content was uploaded" $(\beta=-0.847 ; p<0.000)$, which were all control variables, had a negative impact on the popularity of video content. Otherwise, mini-album sales positively affected the popularity of video content ( $\beta=1.655 ; p<0.000)$, and indicates that the video content of the K-pop star, whose album has sold 
more, has gained more popularity. Model 2 shows that video content without a production company won more popularity from viewers than the original content of $\mathrm{V}$ Live $(\beta=-0.728 ; p<0.01)$. On video content that did not use a production company, viewers can communicate with their favorite streamers in a natural way. Without any script or topic, the spontaneous interaction induced viewers to press the heart button even more actively, and such video content became popular. Model 3 shows that non-series live-streaming had a greater positive impact on the popularity of video content compared to free-style live-streaming $(\beta=1.144 ; p<0.000)$. However, music/choreography had a negative impact on the popularity of video content compared to free-style live-streaming $(\beta=-1.299 ; p<0.000)$. Free-style live-streaming with K-pop stars is only available on V Live; however, music/choreography video content is provided on YouTube and V Live. Exclusive video content won more popularity among viewers. As per Model 4, whether a video is live-streamed had no effect on its popularity.

Table 6. Hierarchical regression (DV = number of hearts).

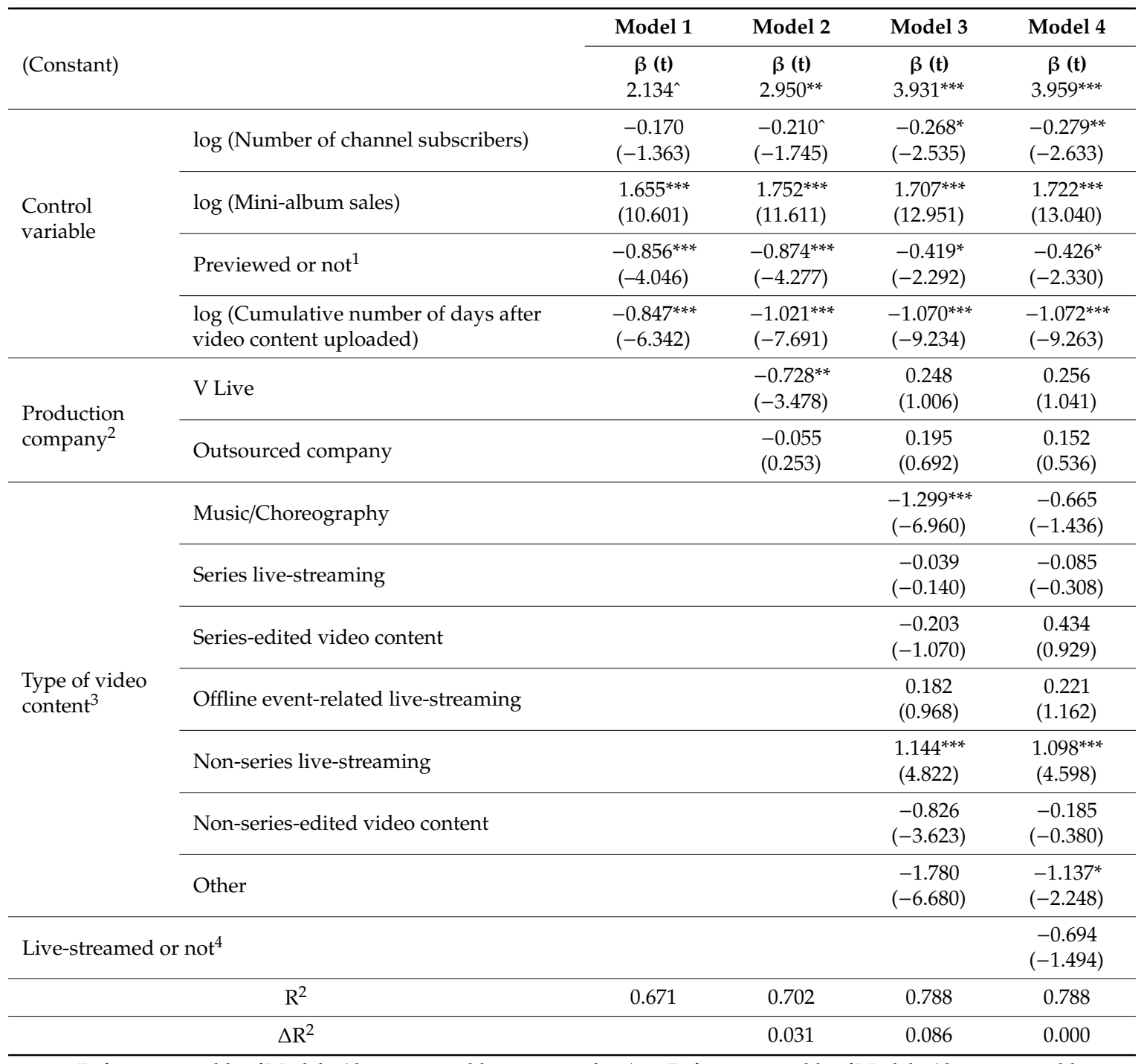

1. Reference variable of Model 1 (dummy variable; previewed $=0$ ); 2 . Reference variable of Model 2 (dummy variable; no production company $=0$ ); 3 . Reference variable of Model 3 (dummy variable; free-style live-streaming $=0$ ); 4. Reference variable of Model 4 (dummy variable; not live-streamed $=0$ ); 5 . Statistical significance: ^ $p<0.10$, ${ }^{*} p<0.05,{ }^{* *} p<0.01,{ }^{* * *} p<0.001$.

When the dependent variable was the number of views, Model 1 of Table 7 reflects that the number of channel subscribers $(\beta=1.041 ; p<0.000)$, mini-album sales $(\beta=0.341 ; p<0.05)$, which were the control variables, positively affected the popularity of video content. Model 2 reflects that 
video content without a production company became more popular than video content produced by V Live $(\beta=-0.878 ; p<0.01)$, whereas that produced by outsourced companies such as an entertainment management agency was viewed more than video content without any production companies $(\beta=0.241 ; p<0.05)$. Model 3 shows that non-series live-streaming $(\beta=0.488 ; p<0.01)$ was played more than free-style live-streaming. Otherwise, music/choreography $(\beta=-0.460 ; p<0.05)$ and series live-streaming $(\beta=-0.878 ; p<0.01)$ were viewed less than free-style live-streaming. At the same time, Model 4 indicates that the live-streaming video content was played less than the recorded video content $(\beta=-2.574 ; p<0.000)$.

Table 7. Hierarchical regression (DV = number of views).

\begin{tabular}{|c|c|c|c|c|c|}
\hline & & Model 1 & Model 2 & Model 3 & Model 4 \\
\hline & $\log$ (Number of channel subscribers) & $\begin{array}{l}1.041^{* * *} \\
(7.585)\end{array}$ & $\begin{array}{l}1.053^{* * *} \\
(7.753)\end{array}$ & $\begin{array}{l}1.012^{* * *} \\
(7.625)\end{array}$ & $\begin{array}{l}0.970 * * * \\
(7.404)\end{array}$ \\
\hline Control & $\log$ (Mini-album sales) & $\begin{array}{l}0.341^{*} \\
(1.986)\end{array}$ & $\begin{array}{l}0.348^{*} \\
(2.043)\end{array}$ & $\begin{array}{l}0.286^{\wedge} \\
(1.732)\end{array}$ & $\begin{array}{l}0.345^{*} \\
(2.112)\end{array}$ \\
\hline & Previewed or not ${ }^{1}$ & $\begin{array}{c}0.279 \\
(1.198)\end{array}$ & $\begin{array}{c}0.290 \\
(1.259)\end{array}$ & $\begin{array}{l}0.403^{\wedge} \\
(1.760)\end{array}$ & $\begin{array}{l}0.375^{\wedge} \\
(1.665)\end{array}$ \\
\hline & $\begin{array}{l}\text { log (Cumulative number of days after } \\
\text { video content uploaded) }\end{array}$ & $\begin{array}{c}0.120 \\
(0.818)\end{array}$ & $\begin{array}{c}0.079 \\
(0.529)\end{array}$ & $\begin{array}{c}0.044 \\
(0.304)\end{array}$ & $\begin{array}{l}0.035^{*} \\
(0.247)\end{array}$ \\
\hline & Music/Choreography & & & $\begin{array}{l}-0.460^{*} \\
(-1.975)\end{array}$ & $\begin{array}{l}1.890^{* *} \\
(3.303)\end{array}$ \\
\hline & Series live-streaming & & & $\begin{array}{l}-0.878^{* *} \\
(-2.915)\end{array}$ & $\begin{array}{l}-1.062^{* * *} \\
(-3.546)\end{array}$ \\
\hline & Series-edited video content & & & $\begin{array}{c}0.340 \\
(1.433)\end{array}$ & $\begin{array}{l}2.703^{* * *} \\
(4.688)\end{array}$ \\
\hline $\begin{array}{l}\text { Types of video } \\
\text { content }^{3}\end{array}$ & Offline event-related live-streaming & & & $\begin{array}{c}-0.288 \\
(-1.218)\end{array}$ & $\begin{array}{l}-0.146 \\
(-0.622)\end{array}$ \\
\hline Live-streamed & $\operatorname{not}^{4}$ & & & & $\begin{array}{l}-2.574^{* * *} \\
(-4.482)\end{array}$ \\
\hline & $\mathrm{R}^{2}$ & 0.655 & 0.665 & 0.698 & 0.710 \\
\hline & $\Delta \mathrm{R}^{2}$ & & 0.010 & 0.033 & 0.012 \\
\hline
\end{tabular}

1. Reference variable of Model 1 (dummy variable; previewed = 0); 2 . Reference variable of Model 2 (dummy variable; no production company $=0$ ); 3 . Reference variable of Model 3 (dummy variable; free-style live-streaming $=0$ ); 4. Reference variable of Model 4 (dummy variable; not live-streamed $=0$ ); 5 . Statistical significance: ${ }^{\wedge} p<0.10$, ${ }^{*} p<0.05,{ }^{* *} p<0.01,{ }^{* * *} p<0.001$.

\section{Conclusions}

In this section, we summarize the main findings and interpret these findings. Then, we discuss the implications and limitations of this study. Finally, we propose future research. 


\subsection{Main Findings}

We determined the factors of $\mathrm{V}$ Live's contents that affected the popularity of video content. The characteristics of $\mathrm{V}$ Live video content were divided into production company, type of video content, and whether the video content was live-streamed. The popularity of video content was measured by number of comments, hearts, and views. To control the potential bias of dependent variables, additional variables were set as control variables, such as number of channel subscribers, mini-album sales, whether video content was previewed, and cumulative number of days since the video content was uploaded.

The summary of results are as follows. First, mini-album sales, a control variable indicating the popularity of K-pop groups, had a positive effect on the number of comments, hearts, and views. The greater the popularity of the K-pop group, the more video content $\mathrm{V}$ Live viewers played and the more they commented and clicked on hearts. This study has therefore confirmed that $\mathrm{V}$ Live viewers prefer video content of popular K-pop groups. In other words, it represents the rich-get-richer effect wherein the more popular the group grows, the more popular its video content becomes.

The second finding involves previewed versus non-previewed video content. This control variable had a negative impact on the number of comments and hearts, but a positive impact on the number of views. That is, non-previewed video content received more comments and hearts from $\mathrm{V}$ Live viewers but was less frequently viewed. Of the 620 videos analyzed in this study, $93.4 \%$ were not previewed $(n=579)$, or there was almost 14 times more non-previewed than previewed video content. Moreover, $35.2 \%$ of the non-previewed video contents were free-style live-streaming $(n=204), 22.3 \%$ were Music/Choreography (in which fans watch K-pop stars sing or dance) $(\mathrm{n}=129)$, and $18.1 \%$ were series-edited video content $(\mathrm{n}=105)$. When $\mathrm{V}$ Live live-streaming is previewed, viewers can comment and press the heart button before live-streaming begins. For this reason, comments and hearts begin to accumulate before live-streaming starts; for non-previewed video content, comments and hearts begin to accumulate immediately after live-streaming begins. Despite this time gap, non-previewed video content ultimately received more comments and hearts from viewers than previewed video content. The non-previewed video content gives viewers unexpected interest, which makes them feel more satisfied [26]. When positive emotions such as higher satisfaction are triggered, viewers become more reactive and involved, resulting in actual engagement behavior such as commenting or pressing the heart [27].

Third, video content without a production company gained more popularity than original content produced by V Live ( $\left.\beta_{\text {comments }}=-1.680, \beta_{\text {hearts }}=-0.726, \beta_{\text {views }}=-0.878\right)$, and also received more comments from viewers than video content produced by outsourced companies such as entertainment management agencies $\left(\beta_{\text {comments }}=-0.474\right)$. In all, $87.6 \%(n=191)$ of video contents planned without a production company are free-style live-streaming, on which streamers spontaneously live-stream to chat with viewers, or show their ordinary lives to viewers. This free-style live-streaming video content presents a slice of everyday life of the K-pop star, known as "Meforming [18]". With Meforming content, K-pop stars exhibit how they cope with unpredictable situations as well as life values and feelings. V Live viewers reacted more actively to the type of video content that allows them to peek into K-pop star's "Meforming" video contents, and this kind of video content won popularity with viewers.

Fourth, non-series live-streaming had a greater positive impact on the number of comments, hearts, and views ( $\beta_{\text {comments }}=0.974, \beta_{\text {hearts }}=1.144, \beta_{\text {views }}=0.488$ ). Non-series live-streaming includes original V Live content such as "Lie-V," "Eat Together," and "Orgel Live," and video content produced by outsourced companies such as "Cooking Star (i.e., video content that a K-pop star cooks)." Video content produced by V Live and outsourced companies requires more effort in production than that made without a production company. According to [17], video content that required more effort in production attracted more viewers than the kind made without a production company. The non-series live-streaming produced by V Live and outsourced companies covers various topics and is produced using a range of broadcasting techniques. In other words, V Live viewers favored either a type of video 
content that allowed them to interact with K-pop stars or a type of live-streaming that was different from existing broadcasting, consistent with the results of [28].

Fifth, $49.7 \%$ of the 620 video contents were live-streamed content $(\mathrm{n}=308)$, and $50.3 \%$ were edited content $(n=312)$, and the difference had a significant impact on all three dependent variables ( $\mathrm{p}_{\text {comments }}<0.000, \mathrm{p}_{\text {hearts }}<0.10, \mathrm{p}_{\text {views }}<0.01$ ). For comments and hearts, the number was higher when it was live-streaming content, while for views, the number was higher when it was recorded video content. Our evidence supports that commenting and pressing "hearts" are ways to express viewers' intentions and emotions [29]. For example, if a streamer asks viewers how they spent a day, what they ate for dinner, how good the newly released album is and so on, viewers can answer through comments and express positive emotions through hearts in real time. That is, video content that enables two-way interaction between a streamer and viewers more effectively drives comments and hearts. On the other hand, it can be inferred that the length of video content causes a higher number of views. The recorded video content (not live-streamed) is at least 15 seconds to less than an hour long, but the live-streaming content is about an hour long on an average. That is, the recorded video content is even shorter than live-streaming, and this indicates that there is less pressure to repeat recorded video content than live-streaming content.

\subsection{Limitations and Implications}

This study has its limitations. First, because it focuses on the top five Star channels, the research findings do not account for factors of video content of other Star channels, beauty channels, classical music channels, or channels in other genres. A "long-tail" phenomenon through which niche content becomes more popular has recently been identified in the new media environment [30,31]. In future research, it will be necessary to understand the characteristics of video contents on low-ranking channels that provide incredible content. In other words, by analyzing how low-ranking channels produce and provide video content on trending topics, it will be possible to separate their identities from those of high-ranking channels to discover the characteristics of video content provided only on low-ranking channels.

Second, in this study, due to data being directly obtained from V Live, results could not be interpreted form the perspective of $\mathrm{V}$ Live viewers. Based on this study's findings, future studies will need to collect data directly from $\mathrm{V}$ Live viewers.

Third, data for dependent variables (number of comments, hearts, and views) are cumulative totals calculated from the date of video content uploaded. In other words, the number of comments, hearts, and views collected before, during, and after live-streaming cannot be distinguished for each point in time. In future research, it will be necessary to use a new technique to collect data in real time. If data are collected before, during, and after live-streaming, the relationship between content factor and popularity of video content can be explained more concretely.

Despite these limitations, our results offer key implications for academics and managers.

This study adds to our theoretical understanding in new media services and video contents. Although past studies have focused on user-generated, game-oriented, and SNS-based live-streaming services, this study investigated V Live, the only live-streaming service that is specific to the entertainment industry. Moreover, we diversified characteristics of video content based on three categories: production company, type of video content, and if it was live-streamed, and obtained a total of 13 sub-items. Compared to past studies that focused only on types of video content, the categories of video content of this study are more detailed. At a time when a lot of video content is simultaneously available through a variety of online video platforms, our study will serve an opportunity to classify video content from varied perspectives.

This study furthers our understanding of the popularity of video content, and we believe that it can serve as a foundation to understand how to produce popular video content for content providers. We estimated the "pure effect" of video content that leads in popularity of video content, controlling for additional factors such as the popularity of K-pop star. As per the results, not-previewed video content, 
interactive video content, and novel video content with high-filming quality gains popularity from viewers. Recently, $\mathrm{V}$ Live is generating revenue by providing exclusive video content through paid channels, and the revenue has been increasing. In other words, content providers who are concerned about profitability of video content can distribute higher budgets to produce this video content and plan countermeasures.

Author Contributions: Conceptualization, methodology, writing-review \& editing: S.W.L., Data collection, data analysis, writing-original draft: M.H. All authors have read and agreed to the published version of the manuscript.

Funding: This research received no external funding.

Conflicts of Interest: The authors declare no conflict of interest.

\section{References}

1. Kim, S.C.; Lee, S.E.; Choi, M.; Kim, S.W.; Koo, H.M. Snack Media Industry Trend Report. Volume 1. Available online: http://www.rapa.or.kr/modules/board/bd_download.asp?idx=4774 (accessed on 6 June 2018).

2. Hong, S.W.; Hae, M.Y.; Cho, S.H. 2017 Report on Trends in Performance and Art. Available online: https://www.gokams.or.kr:442/05_know/data_view.aspx?Idx=927\&txtSearchStr=\&ddlSearchSel= (accessed on 6 May 2018).

3. Jin, H.J. Evolution of V Live Content: Virtual Reality Content. Available online: http://www.dt.co.kr/contents. html?article_no=2017102502101031043002 (accessed on 7 December 2018).

4. Kim, D.W. More than 80,000 People Have Watched Seong-Jin Cho's Showcase Via Live-Streaming. Available online: http://www.donga.com/news/article/all/20161220/81941744/1 (accessed on 6 June 2018).

5. Ahn, S. BTS Performs at Historic Sold-Out Wembley Concert. Available online: http://www.koreaherald. com/view.php?ud=20190602000198 (accessed on 7 December 2018).

6. Naver. Quarterly and Annual Report 2017. Available online: https://www.navercorp.com/investment/ earningsRelease (accessed on 14 April 2019).

7. Lee, M.J. "Heart Work" for My Entertainer, V Live for 10s and Fandom. Available online: $\quad h t t p: / / m a g a z i n e \cdot h a n k y u n g . c o m / b u s i n e s s / a p p s / n e w s ? p o p u p=0 \& n i d=01 \& c 1=1013 \& n k e y=$ 2018082001186000111\&mode=sub_view (accessed on 7 December 2018).

8. Kim, T.G. The Two Biggest Sales of Domestic Video Apps, Pooq and V Live. Available online: http://www. yonhapnews.co.kr/bulletin/2017/09/13/0200000000AKR20170913079700033.HTML (accessed on 6 June 2018).

9. Lee, G.T. K-Pop and the Global Active Audience: The Transnationality of the Naver Webcast Service "V-Live". Korean Assoc. Arts Manag. 2016, 39, 33-65.

10. Scheibe, K.; Fietkiewicz, K.J.; Stock, W.G. Information behavior on social live-streaming services. J. Inf. Sci. Theory. Pract. 2016, 4, 6-20. [CrossRef]

11. Oh, J.; Youn, H.; Yoon, H. A Study on practical use of internet broadcast content. In Proceedings of the Korea Content Society, Chungbuk, Korea, 21-22 November 2003; pp. 468-473.

12. Hilvert-Bruce, Z.; Neill, J.T.; Sjoeblom, M.; Hamari, J. Social Motivations of Live-streaming viewer engagement. Comput. Human Behav. 2018, 84, 58-67. [CrossRef]

13. Yu, E.; Jung, C.; Kim, H.; Jung, J. Impact of viewer engagement on gift-giving in live-video streaming. Telematic. Inform. 2018, 35, 1450-1460. [CrossRef]

14. Chen, C.; Lin, Y. What drives live-stream usage intention? The perspectives of flow, entertainment, social interaction, and endorsement. Telemat. Informat. 2018, 35, 293-303. [CrossRef]

15. Hu, M.; Zhang, M.; Wang, Y. Why do audiences choose to keep watching on live video streaming platforms? An explanation of dual identification framework. Comput. Human Behav. 2017, 75, 594-606. [CrossRef]

16. Welbourne, D.J.; Grant, W.J. Science communication on YouTube: Factors that affect channel and video popularity. Public Underst. Sci. 2016, 25, 706-718. [CrossRef] [PubMed]

17. Friedlaender, M.B. Streamer motives and user-generated content on social live-streaming services. J. Inf. Sci. Theory Pract. 2017, 5, 65-84.

18. Tang, J.C.; Venolia, G.; Inkpen, K.M. Meerkat and periscope: I stream, you stream, apps stream for live streams. In Proceedings of the 2016 CHI Conference on Human Factors in Computing Systems, San Jose, CA, USA, 7-12 May 2016; pp. 4770-4780. 
19. Figueiredo, F.; Almeida, J.M.; Benevenuto, F.; Gummadi, K.P. Does content determine information popularity in social media? A case study of YouTube videos' content and their popularity. In Proceedings of the 32th Annual ACM Conference, Toronto, ON, Canada, 26 April-1 May 2014.

20. Burgess, J.E.; Green, J.B. YouTue: Online Video and Participatory Culture; Press: Cambridge, UK, 2009; ISBN 978-0-7456-4478-3.

21. Lee, J.J. The Dark Shadows of the YouTube Creators' World. Available online: http://www.mediatoday.co.kr/ ?mod=news\&act=articleView\&idxno=146327 (accessed on 3 March 2019).

22. Hong, S.Y. Why Making Money on YouTube is Tough? Available online: http://www.econovill.com/news/ articleView.html?idxno=334418 (accessed on 17 August 2018).

23. Hollenbaugh, E.E.; Ferris, A.L. Facebook self-disclosure: Examining the role of traits, social cohesion, and motives. Comput. Human Behav. 2014, 30, 50-58. [CrossRef]

24. Cheung, C.M.; Chiu, P.; Lee, M. Online social networks: Why do students use Facebook? Comput. Hum. Behav. 2011, 27, 1337-1343. [CrossRef]

25. Kim, Y.; Sohn, D.; Choi, S.M. Cultural differences in motivations for using social networking sites: A comparative study of American and Korean college students. Comput. Hum. Behav. 2010, 22, 365-372.

26. Chatterjee, P. Advertised versus unexpected next purchase coupons: Consumer satisfaction, perceptions of value, and fairness. J. Prod. Brand Manag. 2007, 16, 59-69. [CrossRef]

27. Chen, Y. The sustainable development of social media contents: An analysis of concrete and abstract information on cultural and creative institutions with "artist" and "ordinary people" positioning. Sustainability 2019, 11, 4131. [CrossRef]

28. Lee, J.H.; Lee, C.F. Extension of TAM by perceived interactivity to understand usage behaviors on ACG social media sites. Sustainability 2019, 11, 5723. [CrossRef]

29. Marwick, A.E.; Boyd, D. I tweet honestly, I tweet passionately: Tweeter users, context collapse, and the imagined audience. New Media Soc. 2010, 13, 114-133. [CrossRef]

30. Yoon, Y. A Study on increased user autonomy and new content paradigm according to media fragmentation. J. Korea Entertain. Ind. Assoc. 2015, 9, 43-56. [CrossRef]

31. Napoli, P.M. Audience Evolution: New Technologies and the Transformation of Media Audiences; Columbia University Press: New York, NY, USA, 2011; ISBN 978-023-115-034-7. 